\title{
Síndrome Bazex-Dupré-Christol: serie de casos
} Bazex-Dupré-Christol syndrome: Case series

\author{
Dra. Niní Yesenia Arévaloa, Dra. María M. Buján ${ }^{a}$ Dra. Andrea B. Cervini y Dr. Adrián M. Pierinia
}

\begin{abstract}
RESUMEN
El síndrome de Bazex-Dupré-Christol es una genodermatosis ligada al cromosoma $\mathrm{X}$, la cual se caracteriza por presentar hipotricosis congénita, hipohidrosis, atrofodermia folicular, múltiples quistes de millium y carcinomas basocelulares. Presentamos a una niña y su familia con este síndrome. La paciente y sus hermanos de 5 meses de edad y de 17 años de edad presentaban múltiples quistes de millium e hipotricosis de las cejas y el cuero cabelludo. Su hermano de 8 años presentaba quistes de millium y atrofodermia folicular. Su madre presentaba hipohidrosis, hipotricosis congénita del cuero cabelludo y las cejas, así como también una lesión tumoral en la región paranasal derecha compatible con carcinoma basocelular. Destacamos la importancia del diagnóstico y del seguimiento clínico de estos niños por la posibilidad de desarrollar carcinomas basocelulares.

Palabras clave: sindrome de Bazex-Dupré-Christol, hipotricosis, hipohidrosis, atrofodermia folicular y carcinoma basocelular.
\end{abstract}

\begin{abstract}
Bazex-Dupré-Christol syndrome is an X-linked dominantly inherited disorder characterized by congenital hypotrichosis, hypohidrosis, follicular atrophoderma, multiple milia and basal cell carcinomas. We present a girl and her family with this syndrome. Our patient, her 5 month old brother and her 17 year old brother had multiple milia and scalp and eyebrows hypotrichosis. Her 8 year old brother had multiple milia and follicular atrophoderma. Her mother had hypohidrosis and congenital scalp and eyebrows hypotrichosis, as well as a right paranasal lesion suggestive of basal cell carcinoma. We emphasize the importance of precise diagnosis and clinical follow up of these patients due to the possibility of developing basal cell carcinomas.

Key words: Bazex-Dupré-Christol syndrome, hypotrichosis, hypohidrosis, follicular atrophoderma and basal cell carcinoma.
\end{abstract}

http:/ /dx.doi.org/10.5546/aap.2015.e256

a. Servicio de Dermatología. Hospital Nacional de Pediatría "Prof. Dr. Juan P. Garrahan", Buenos Aires, Argentina.

Correspondencia:

Dra. María Marta Buján, mariambujan@yahoo.com

Financiamiento: Ninguno.

Conflicto de intereses: Ninguno que declarar.

Recibido: 12-11-2014

Aceptado: 16-4-2015

\section{INTRODUCCIÓN}

El síndrome de Bazex-Dupré-Christol (SBDC) es una genodermatosis poco frecuente de herencia dominante ligada al cromosoma X. Clínicamente, estos pacientes suelen presentarse con atrofodermia folicular, hipotricosis, hipohidrosis, múltiples quistes de millium y carcinomas basocelulares de aparición precoz.

\section{CASO CLÍNICO}

Paciente de sexo femenino, de 2 años de edad, que consultó a nuestro Servicio por hipotricosis congénita del cuero cabelludo y las cejas asociada a una disminución de la sudoración. Como antecedentes familiares, la niña tenía a sus tres hermanos, su madre y 3 tíos maternos con manifestaciones clínicas similares. En el examen físico de la paciente, se observaban múltiples quistes de millium en la nariz y las mejillas e hipotricosis del cuero cabelludo y las cejas (Figura 1). Su hermano menor, de 5 meses de edad, tenía rasgos clínicos similares: múltiples quistes de millium e hipotricosis del cuero cabelludo y las cejas (Figura 2). Su hermano de 8 años de edad presentaba quistes de millium localizados en los párpados, lesiones de atrofodermia en ambas mejillas y en la base de la nariz (Figura 3) y, en el dorso de ambas manos, depresiones puntiformes compatibles con atrofodermia folicular. El hermano de 17 años de edad presentaba múltiples quistes de millium en las mejillas y los párpados e hipotricosis de las cejas y el cuero cabelludo (Figura 4). La madre del niño refería hipohidrosis y presentaba hipotricosis congénita del cuero cabelludo y las cejas, así como una lesión tumoral en la región paranasal derecha, en cuya dermatoscopía se observaron vasos arboriformes y una pigmentación azul grisácea, que se interpretó como un posible carcinoma basocelular, por lo que se la derivó a un hospital de adultos para su extirpación.

Con los hallazgos clínicos descritos en esta familia, se realizó el diagnóstico de SBDC.

A los niños se les indicó medidas de fotoprotección (usar protector solar, evitar el sol entre las 11 y las $16 \mathrm{~h}$, usar ropa y sombrero 
Figura 1. Paciente de 2 años de edad con quistes de millium en la nariz y las mejillas e hipotricosis del cuero cabelludo

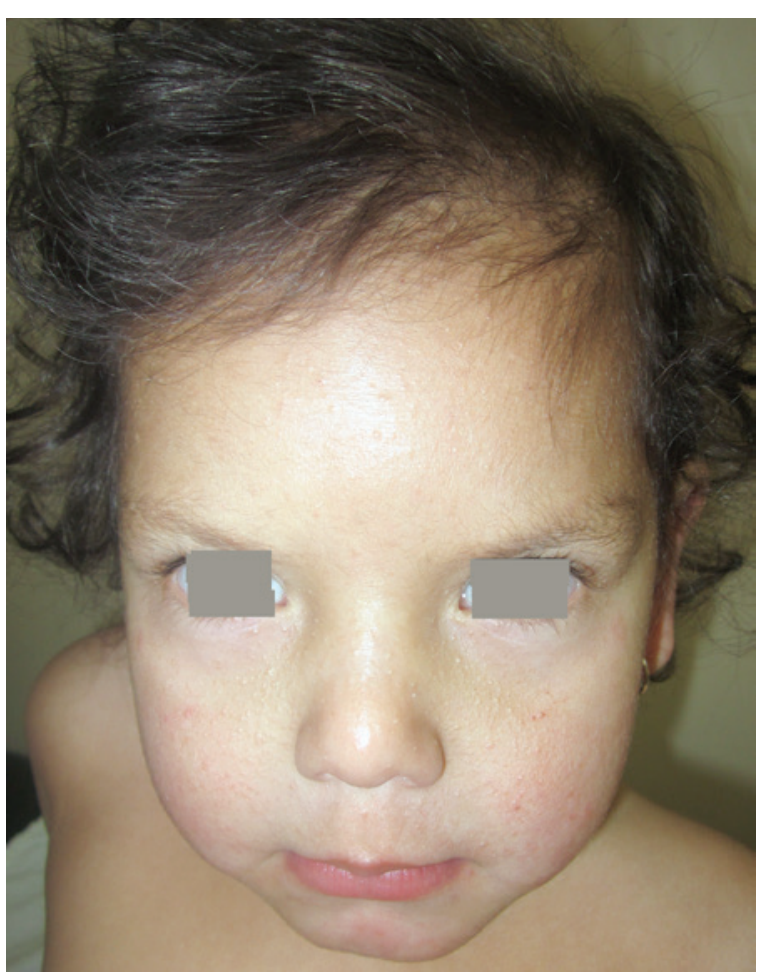

Figura 2. Paciente de 5 meses de edad con quistes de millium, hipotricosis en las cejas y el cuero cabelludo

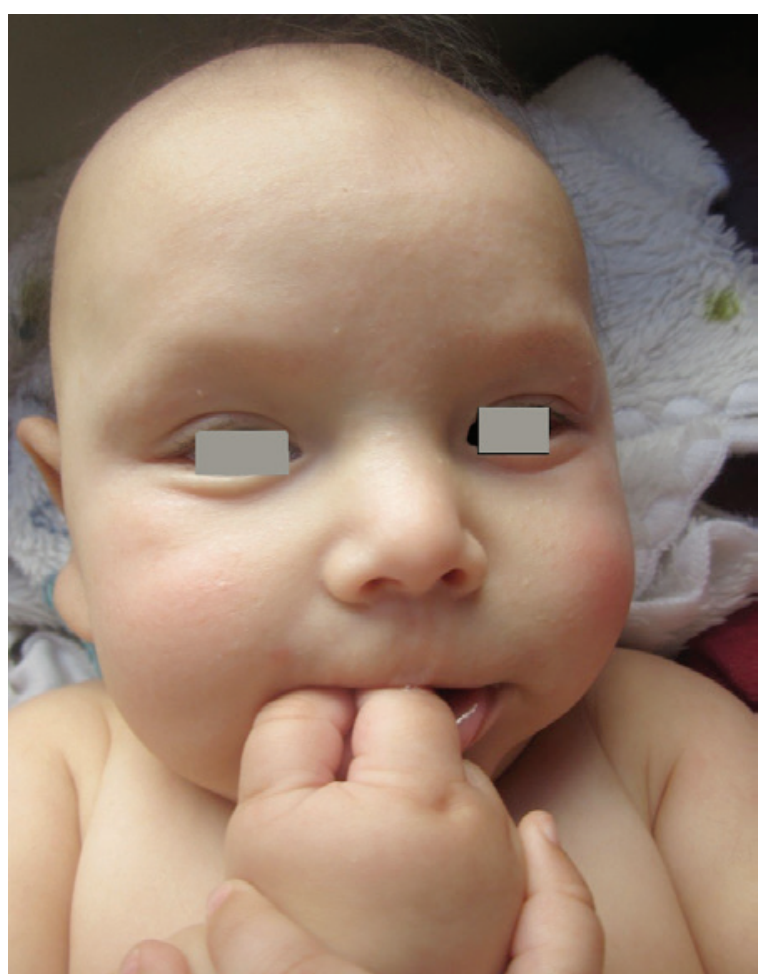

adecuados). En la actualidad, continúan siendo evaluados periódicamente en nuestro Servicio con la finalidad de detectar la aparición de lesiones malignas. La madre fue derivada a un hospital de adultos con el fin de poder realizarse sus controles pertinentes.

Figura 3. Hermano de 8 años de edad con múltiples quistes de millium en los párpados y atrofodermia en la base de la nariz y las mejillas

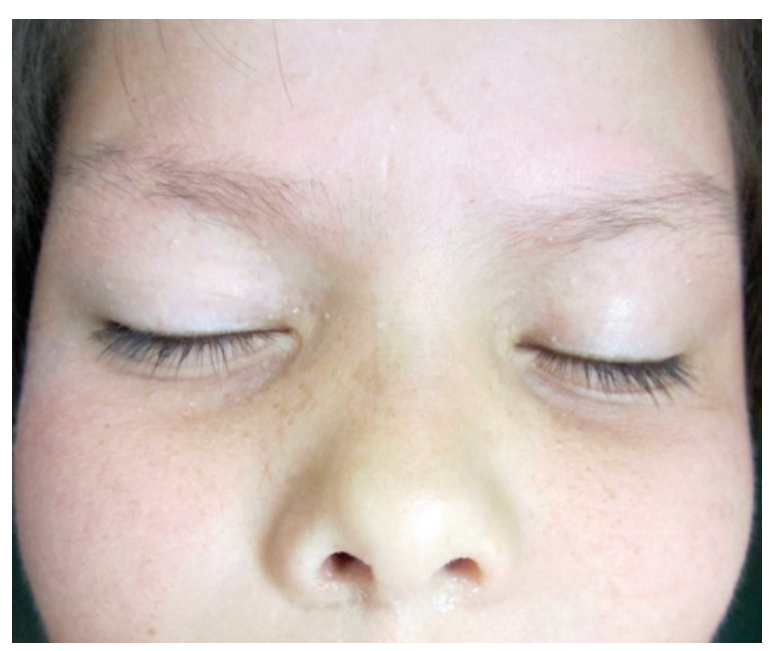

Figura 4. Paciente de 17 años de edad con múltiples quistes de millium en las mejillas y los párpados e hipotricosis de las cejas

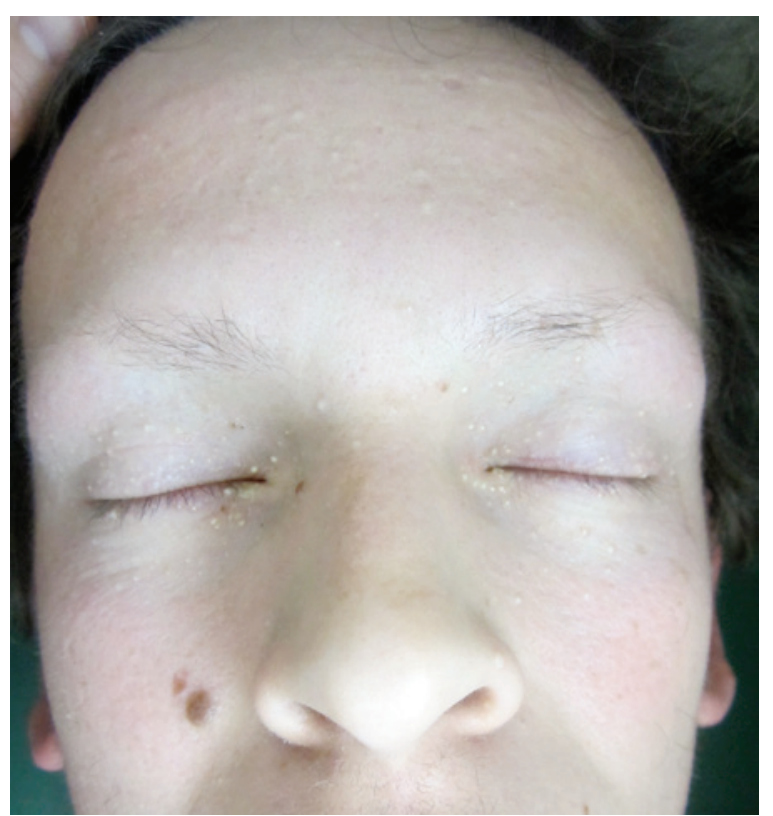




\section{DISCUSIÓN}

En 1966, Bazex y col., ${ }^{1}$ describieron un nuevo síndrome caracterizado por hipotricosis congénita, atrofodermia folicular y carcinomas basocelulares. ${ }^{2-4}$ Los quistes de millium, la hiperpigmentación facial, la hipohidrosis y los tricoepiteliomas han sido también descritos en este síndrome. ${ }^{3,5,6} \mathrm{Su}$ expresividad es variable entre diferentes personas afectadas y esto se explicaría por el fenómeno de lyonización. ${ }^{7}$

El SBDC se hereda de forma dominante ligada al cromosoma $X$, y se localiza en el sitio Xq24-27 el gen mutado, denominado BZX, responsable de este síndrome. ${ }^{8}$

La atrofodermia folicular consiste en pequeñas depresiones puntiformes centradas en el infundíbulo del folículo piloso, localizadas con más frecuencia en el dorso de las manos y los pies, en la superficie de la extensión de los codos y las rodillas, y ocasionalmente, en la cara. ${ }^{7,9} \mathrm{Se}$ presenta en alrededor del $85 \%$ de los pacientes y puede observarse desde el nacimiento o más tardíamente. ${ }^{10,11} \mathrm{Si}$ bien la atrofodermia folicular es muy característica, no es específica de este síndrome, ya que ha sido también asociada a la atrofodermia vermiculata, condrodisplasia punctata, síndrome de Rombo y síndrome del carcinoma de células basales nevoide, entre otros. ${ }^{9}$ En nuestros pacientes, el niño de 8 años era el único que la presentaba y esta se encontraba en el dorso de ambas manos, en la nariz y en las mejillas.

La hipotricosis afecta a, aproximadamente, el $85 \%$ de los pacientes y puede comprometer el cuero cabelludo, las cejas, las pestañas, las axilas, el pubis, entre otras áreas del cuerpo. Por lo general, se presenta en la infancia precoz y mejora con la edad. El cabello es delgado, irregular, de color marrón claro y, dentro de las alteraciones del tallo piloso, se encuentran descritos el pili torti y la tricorrexis nodosa. ${ }^{9,11}$ Todos nuestros pacientes presentaban hipotricosis y solo en uno de ellos había mejorado (hermano de 8 años) con la edad.

La hipohidrosis se ha descrito en alrededor del $55 \%$ de los pacientes. ${ }^{12}$ Puede afectar solamente a la cara o ser generalizada. En el caso presentado, además de nuestra paciente, también referían hipohidrosis su madre y tres tíos maternos.

Los carcinomas de células basales se presentan en alrededor del $40 \%$ de los pacientes durante la segunda o tercera década de la vida y se localizan, en su mayoría, en áreas fotoexpuestas, como la cara y el cuello. ${ }^{11,13,14}$ Se debe examinar periódicamente a los pacientes con este síndrome, con el fin de detectar de forma precoz la aparición de este tipo de tumores. En la dermatoscopía, los carcinomas basocelulares presentan patrones específicos, como múltiples puntos o glóbulos de color azul-grisáceo y vasos arboriformes. ${ }^{15}$

Los quistes de millium suelen afectar la cara $\mathrm{y}$, con menor frecuencia, las extremidades y el tronco, y pueden ser de aparición congénita o durante la infancia. ${ }^{11}$ Nuestra paciente y sus tres hermanos presentaban múltiples quistes de millium en la cara.

Entre los diagnósticos diferenciales del SBDC, se encuentran el síndrome de Gorlin, la condrodisplasia punctata y el síndrome de Rombo, entre otros. ${ }^{5}$ El síndrome de Gorlin se caracteriza por atrofodermia folicular, quistes mandibulares, cutáneos y ováricos, junto con una gran variedad de alteraciones esqueléticas, neurológicas y oculares, y aparición de múltiples carcinomas basocelulares en las primeras décadas de la vida. ${ }^{7}$ A diferencia del síndrome de Gorlin, el SBDC no se manifiesta con presencia de hoyuelos palmoplantares o anomalías esqueléticas. ${ }^{3}$ La condrodisplasia punctata se caracteriza por osteopoiquilosis, atrofodermia, asociado a dismorfias craneofaciales, talla baja, cataratas y alteraciones cardíacas. El síndrome de Rombo se presenta con atrofodermia vermiculata, hipotricosis, tricoepiteliomas, carcinomas basocelulares y vasodilatación periférica con cianosis.

El tratamiento de los pacientes con SBDC se basa en la pesquisa precoz de los carcinomas basocelulares y su tratamiento oportuno (exéresis quirúrgica, imiquimod, 5 fluorouracilo, terapia fotodinámica, etc.). Los quistes de millium pueden tratarse con ácidos retinoicos locales y su extracción manual. Se debe enfatizar en la importancia de la fotoprotección de estos pacientes y sugerirles el uso de pantallas solares, ropas y sombreros adecuados, así como también evitar jugar al sol en el horario de mayor irradiación solar (11-16 h).

\section{CONCLUSIÓN}

Si bien el SBDC es una genodermatosis poco frecuente, presenta características clínicas definidas, que permiten arribar a su diagnóstico en edades tempranas de la vida. Se debe realizar un adecuado asesoramiento genético de estas familias debido al carácter hereditario de esta entidad, así como también un seguimiento estricto de estos pacientes debido a la mayor posibilidad de desarrollar carcinomas basocelulares. 


\section{REFERENCIAS}

1. Bazex A, Dupré A, Christol B. Atrophodermic folliculaire, proliférations baso-cellulaires et hypotrichose. Ann Dermatol Syphiligr (Paris) 1966;93(3):241-54.

2. Castori M, Morrone A, Kanitakis J, Grammatico P. Genetic skin diseases predisposing to basal cell carcinoma. Eur J Dermatol 2012;22(3):299-309.

3. Abuzahra F, Parren LJ, Frank J. Multiple familial and pigmented basal cell carcinomas in early childhood - BazexDupré-Christol syndrome. J Eur Acad Dermatol Venereol 2012;26(1):117-21.

4. Parren LJ, FrankJ. Hereditary tumour syndromes featuring basal cell carcinomas. Br J Dermatol 2011;165(1):30-4.

5. Parren LJ, Abuzahra F, Wagenvoort T, Koene F, et al. Linkage refinement of Bazex-Dupré-Christol syndrome to an 11.4-Mb interval on chromosome Xq25-27.1. $\mathrm{Br} J$ Dermatol 2011;165(1):201-3.

6. Plosila M, Kiistala R, Niemi KM. The Bazex syndrome: follicular atrophoderma with multiplebasal cell carcinomas, hypotrichosis and hypohidrosis. Clin Exp Dermatol 1981;6(1):31-41.

7. Maira ME, Pérez L, Hevia Parga H, Rohmann Knopp I. Síndrome de Bazex. Rev Chil Dermatol 1996;12(4):201-4.

8. OMIN. Online Mendelian Inheritance in Man. Baltimore: Johns Hopkins University;2015. [Acceso: 30 de marzo de 2015]. Disponible en: http://omim.org/geneMap/ $X / 536$ ?start $=-3 \&$ limit $=10$ \&highlight $=536$.
9. Barcelos AC, Nico MM. Bazex-Dupré-Christol syndrome in a 1-year-old boy and his mother. Pediatr Dermatol 2008;25(1):112-3.

10. Gambichler T, Hoffjan S, Altmeyer P, Bechara FG. A case of sporadic Bazex-Dupré-Christol syndrome presenting with scarring folliculitis of the scalp. $\mathrm{Br} J$ Dermatol 2007;156(1):184-6.

11. Torrelo A, Sprecher E, Mediero IG, Bergman R, et al. What syndrome is this? Bazex-Dupré-Christol syndrome. Pediatr Dermatol 2006;23(3):286-90.

12. Goeteyn M,Geerts ML,Kint A,DeWeertJ.TheBazex-DupréChristol syndrome. Arch Dermatol 1994;130(3):337-42.

13. Kidd A, Carson L, Gregory DW, de Silva D, et al. A Scottish family with Bazex-Dupré-Christol syndrome: follicular atrophoderma, congenital hypotrichosis, and basal cell carcinoma. J Med Genet 1996;33(6):493-7.

14. Gréco M, Bessaguet-Küpfer I, Bourrigan M, Plantin P. Grains de milium diffus chez un nourrisson révélateurs d'un syndrome de Bazex, Dupré et Christol. Ann Dermatol Venereol 2006;133(8-9 Pt 1):697-9.

15. Tiodorovic-Zivkovic D,Zalaudek I, Ferrara G, Giorgio CM, et al. Clinical and dermatoscopic findings in Bazex-DupréChristol and Gorlin-Goltz syndromes. J Am Acad Dermatol 2010;63(4):722-4. 